\title{
Against the magnanimous in medical ethics
}

\author{
Michael H Kottow, MD Santiago, Chile
}

\section{Author's abstract}

Supererogatory acts are considered by some to be part of medicine, whereas others accept supererogation to be a gratuituous virtue, to be extolled when present, but not to be demanded. The present paper sides with those contending that medicine is duty-bound to benefit patients and that supererogation/altruism must per definition remain outside and beyond any role-description of the profession. Medical ethics should be bound by rational ethics and steer away from separatist views which grant exclusive privileges but also create excessive demands, way beyond what physicians perform or are willing and able to offer.

\section{Introduction}

Notwithstanding increased regulation and tightening of economic constraints in different kinds of medical systems, there seems to be a pervading distrust among health professionals to see their activities discussed in merely contractual terms. Recurring discussions on supererogation appear to reflect the need to see health services in a light more ample and generous than a contract between health providers and patients. Even though patient rights and autonomy carry the day over arguments in favour of paternalism, this egalitarian stance has not foreclosed the view that the patient is a vulnerable human being taken care of by a socially and often economically more potent physician, who by this very asymmetry is morally bound to act in a supererogatory fashion.

The issue has strong intuitive components and therefore makes use of a variegated and often illdefined nomenclature. At least five concepts appear in the context of these discussions: beneficence, Levitism, Samaritanism, supererogation and altruism.

\section{Beneficence}

Literally, beneficence is an act that promotes benefits, goods, utility. Most beneficial acts accrue in the

\section{Key words}

Beneficence; Levitism; Samaritanism; supererogation; altruism; paternalism. institutionalised atmosphere of everyday social intercourse. Socialised human beings live in an environment of moral expectations that include a sense of security and lack of fear, and the vague but operational sensation that mutual aid is available at least on a minimal-cost basis (1). Human collectives can be understood to take for granted a certain tendency towards mutual aid or minimal decency (1), which goes without saying and only becomes visible when it is disregarded or transgressed. Human acts are by definition beneficial, for they foster someone's interests. They will be morally beneficial when they benefit some other than the agent. In medicine, acts are performed freely and by mutual consent, hardly qualifying as medical unless they benefit the patient, it therefore appearing redundant to analyse them in terms of beneficence.

\section{Levitism}

The New Testament parable refers to a Levite as someone to be understood as a person bound by a clear and explicit set of rules. Non-compliance with the rules characterises what has been called a Bad Levite (2). Levitism consists basically in obeisance to law and regulations, Bad Levitism being the failure to benefit or the omission of harm preventing acts within this normative setting. Peculiar to the Bad Levite situation is the presence of some kind of bonding to the victim. To go beyond the rules would create the Good Levite, a denomination that has been replaced by that of (Good) Samaritan. In Levitism, agent and patient are involved in a relationship entailing an implicit or weakly explicit kind of contract. Doctors who abandon their patients in the course of treatment are not Bad Levites, they are simply violating moral imperatives, professional standards and legal requirements. But if the physician omits to offer help or denies assistance to a patient he has not been previously responsible for, he is failing to enter a contractual relationship. His attitude thus rather falls under the analysis of Samaritanism, not Levitism, unless doctors are considered ex officio to be a potential contractual partner of anyone requiring medical assistance, a view to be discussed later on. Up to this point, Levitism 
seems an inadequate category for evaluating medical acts.

\section{Samaritanism}

Samaritanism refers to attitudes taken when help is called for in situations devoid of any overt or covertly agreed obligation. When help is given, the agent is a Good Samaritan, failure to assist is considered Bad Samaritanism. Since there is no evaluative or contractual norm for Samaritanism, there will be no equivalent to the rule-abiding Levite. An act is Good Samaritanism when it gratuitously averts harm from a victim, and it is Bad Samaritanism if an individual, being in a position but not under obligation to help, chooses not to do so. Three aspects serve to evaluate Samaritan acts: 1) Will the act produce benefits or prevent harm? Included here are considerations about the amount, imminence and reversibility of harm; 2 ) What amount of effort need the agent exact in order to be a Good Samaritan? What is the effectivity and indispensability of the agent's intervention, and 3) What is the moral and legal atmosphere sustaining Samaritanism (2)?

As to point 3), there is hardly a defensible moral stance for preferring Bad over Good Samaritanism. Certain ethical constructions might be indifferent to this problem, but there will always be a moral bonus on assisting someone in need or distress rather than remaining oblivious. Legal sanctions for failing to prevent harm do exist in many countries but they only serve to transform Good Samaritanism from a moral issue into one of abiding by the law, and leave unresolved those cases where not harm, but lack of benefit is at issue. As for points 1) and 2) they can be conflated in a sophisticated cost/benefit analysis, where harm prevented is matched with efforts exerted by the Samaritan.

How does this affect the issue of professionalism in medicine? Physicians have primary obligations to their patients, that is, to those in distress who seek medical assistance. But their duties do not end there, for they have been educated (trained is the often-used and perhaps more accurate word) and later even hired by society to cover services beyond the individual needs of the sick. Such more general tasks include preventive medicine, public health and spontaneous assistance in emergencies. No one would excuse a physician for failing to answer a doctor-in-the-house call in a theatre, for example. Nor can he fail to respond to medical emergencies he happens to witness, or to offer his services in catastrophes that occur within his radius of potential action. The physician's role includes the legitimate expectations that he offer his services to prevent harm in many situations that have not been contractually formalised. But, since these actions fall under the overt social agreement of role-fulfillment, there is no reason to exempt them from being dutybound. Such actions are no longer susceptible to a Samaritan analysis; they are at least latently contractual and can be judged in the light of Levitism (3).

\section{Supererogation and altruism}

All previously discussed instances refer to the dispensation of welfare or well-being on the basis of assisting the victims by reducing or averting harmful influences. Common to all descriptions is that they obtain under tolerable cost-benefit conditions, that is, Levitism, Samaritanism and beneficence do not require costs from the agent in any way equivalent, much less in excess of the harm being averted. In fact, to be a Good Samaritan does not mean to deflect harm from the victim to oneself, but to give essential help without endangering the agent's well-being, much less his welfare. Such considerations presuppose that costs incurred by the agent and benefits accrued to the victim are measurable and in some ways comparable.

Some of these features no longer obtain for supererogation. By definition, supererogatory acts go well beyond any contractual obligation and, in fact, they exceed moral or social expectations, for to comply in one's donations to written law or unwritten custom is to erogate adequately, but not superbly; supererogation will only obtain if the contribution exceeds all reasonable expectations. The metacontractual character of supererogation is confirmed by its classification into duty-plus of welfare-promoting supererogation (supererogation proper), generosity or low-cost, well-being promoting supererogation and self-denial or high-cost well-being promotion supererogation $(3,4,5)$.

No clear criteria have been put forth to distinguish between altruism and supererogation. Altruism is defined as the '... willingness to act in consideration of the interests of other persons, without the need of ulterior motives' (6). Or, as 'social behaviour carried out to achieve positive outcomes for another rather than for the self (7). What strikes the eye is that altruism is discussed in terms of willingness, behaviour or intentions of the agent (8), whereas supererogation focusses on the results of generous acts as perceived by the recipient. If someone goes out of her way to help beyond any explicit or implicit obligation, she is being supererogatory, no matter what reasons or intentions her act has. But it will only be an altruistic act if it really stems from the desire to put other-interest before selfinterest. And this intention need not necessarily be efficient in promoting welfare or well-being for the recipient in order to be considered motivationally altruistic.

Not too much should be made of the differentiation between supererogation as donation and altruism as neighbourly concern, for they in fact intermingle, each term being preferred according to the analysis at hand. Psychologists and educators tend to stress altruism, whereas social scientists and economists prefer to discuss supererogation. In health care, altruism would seem to be an inappropriate term for it tends to focus 
on the counterbalance between self and otherinterests, an area that in medicine is extremely difficult to judge and evaluate, and where comparisons are hardly practical (see below). This may be the reason why the medico-ethical literature on this subject tends to conflate altruism and supererogation and use them indistinctly, in an effort to focus more on well-being promoting acts rather than on well-intentioned motives.

\section{Is medicine under obligation of altruism?}

Medicine, by reason of being a profession, has been considered to be under 'duty' of altruism. The justification of such a duty lies in a threefold argument:

1) Medicine is a profession; 2) professionals are immensely more powerful than their clients and therefore must in all fairness give preference to clientinterests over self-interests, and; 3) client-interests are paramount so long as they do not collide with the 'noble' cause that must demand the professional's ultimate loyalty (8).

This position is flawed on a number of points. To begin with, it equates professionalism with accumulation of power. This is a true but only partial feature of professions, the more general proposition being that profession is a sociological definition referring to groups sharing their activities under a number of premisses which include independence, regulation of qualification and training, as well as the securing of generous rewards for services that society values highly. Disproportionate power is a necessary but not sufficient descriptive feature, which does not allow any ethical consequences unless additional moral premisses are introduced. The requirement to efface professional self-interest is not substantiated. As it stands, it appears to be a mere formula of commercial etiquette, requiring professionals, as any other persons, not to take material advantage from being the more privileged and less vulnerable member of a transaction $(9,10)$. The sociological genesis of the term professionalism specifies that professional efforts are centred around activities that society values highly and is therefore willing to reward handsomely, but nothing is said about the 'nobleness' of professional concerns. Even if professionals were required to be self-effacing and ultimately devoted to a noble cause, it still does not follow how individual and societal interests are to be balanced. For the professional's role is to attend individual needs of a certain type, at the same time being under obligation not to neglect general welfare. Now this highly complex discrepancy between individual and collective interests can certainly not be resolved by simply requiring 'service to one's noble cause' to be absolutely predominant, where 'even the interests of the patient or client cannot override what the service demands' (8).

\section{The moral status of professions}

The debate on this issue has been couched in terms of the more fundamental one concerning the existence of medical ethics as distinct from general ethics. Professionals in general, so one side of the argument goes, and physicians in particular, are expected to be morally sound and are measured by the same ethical norm as any other participants in societal activities. In response to this desanctification of medicine, the position is upheld, that medical and a few other professional acts have historically and socially 'built-in' special obligations and requirements of 'better behaviour' $(11,12)$. Such a position is plausible, though it addresses too large an issue to be discussed here. There is little to be said against granting that medicine is, or should be, practised in a special ethical climate, using 'special' to encompass not only that which is peculiar and specific to a job description, but also to include exclusive and sophisticated moral considerations. After all, that is what medical ethics is about. More relevant is the conclusion derived, that this special ethical stance of doctors consists in a 'selfimposed supererogatory altruistic moral obligation to those they serve...'. If supererogatory acts are defined as meta-deontological or duty-plus acts, they cannot be included in a catalogue of medical obligations without ceasing to be supererogatory and converting to role duties. The realm of role duties may be exceptionally ample if medical practice is considered to be more intensely obligation-laden than other activities, but this deontological language must stear clear from issues such as supererogation and altruism, lest it become inextricably contradictory.

\section{Separatist morals for medicine}

The problem is embedded in the more general one of seeing professional morality as diverging from, and even legitimately conflicting with, ordinary morality. It is argued that this divergence is both permissible and obligatory, based on the pecularity of professional values, which lead professional agents to operate in a decisional realm distant from that of everyday morality. Being part of the medical profession becomes exclusively transcendental because it originates the conditions for the possibility of being ethical $(13,14)$. Such a view gives birth and substance to a separatist thesis on professional ethics, creating exclusive moral standards that would not be allowed or demanded outside the profession.

Whereas it is unquestionable that certain professions have moral leeway that is peculiar to them, it is also valid that such a distinction is only permissible as long as it is based on mutual consent and does not violate any rights of those involved. The separatist view has been challenged on grounds that no act, directly or through an institution, is morally legitimate if it violates the basic rights of freedom and well-being (15). Although this discussion centres on permissiveness and not on surplus morality, it does illustrate that professions may have different codes of action and distinct margins of ethical conduct, but that they are 
subject to the same moral guidelines as those underlying ordinary, better called rational, morality (16).

If someone demands altruistic motivations and supererogatory actions from the medical profession, he/she is saying one of two things: either medicine does have specific standards of moral conduct, entailing special rights to infringe, and equally special obligations to exceed, standard rational ethics, or medicine operates on the basis of rational ethics and it is morally justified to give medicine a specific reading. Adopting the separatist view would mean expanding the duty-catalogue of medicine to include the obligation to supererogate. But the fulfillment of a duty, even a special and exquisite one, cannot be described as supererogatory and, analogously, being altruistic by demand may be a useful feature of professional services but it no longer is a virtue for it lacks the element of gratuitousness. A more fundamental argument against separatist views on professional morality is rather more complex, but can be condensed by arguing that professions arise from and are fostered by social environments that obey the mandates of rational morality. Their growth and independence cannot lead to a particular moral code that deviates from such a rational origin. Professional ethics are and must remain a sub-set of rational ethics. Therefore, the final arbiter of professional ethics will not be a separatist view but the common morality based on rationality. The conciliatory option of casting medicine in the framework of common morality but allowing it certain freedom of interpretation is separatism once removed and equally at a loss to justify why such a particular reading of rational morality should be legitimate.

Up to this point it has been argued that medical acts, though apparently prone to appear generously beneficial, fail in fact to fall under any but clearly contractual and role-duty terms, so that normative medical ethics finds no justification for the inclusion of supererogation and altruism to the duty-catalogue of medical services. As for descriptive medical ethics, they certainly can illustrate with casuistics that physicians often are supererogatory, but such a description will allow no prescription, no generalisation and certainly no prediction of medical conduct.

\section{Medicine as a non-magnanimous service}

It remains to be explained and justified why medicine is impervious to the ethics of magnanimity. The main reason seems to be medicine's progressive, and in the last decades vertiginous, departure from the contemplative and therapeutically reticent attitude of Hippocratic medicine: 'the progress of a disease should be so guided, where guidance is needed, that it may develop in the most favourable manner according to its natural tendency' (17). Modern medicine is aggressively counter to processing natural events as is reflected in its bellicose semantics: diseases are attacked, symptoms are combatted, antibiotics (lifedestroyers) are employed, tumours are destroyed. Such a warlike strategy acquires a special flavour because it is not fought on a neutral battleground nor is the medical agent the direct aggressor. Rather, natural processes are re-modelled by medicine in the terrain offered by the patient who thus incurs all risks and costs. Not only are patient-costs involved unavoidably hard to comensurate, but benefits to be expected are equally difficult to gauge and may remain absent. Such a roughly sketched scenario eventually will need much honing, but it might at present suffice to indicate that the cost/benefit analysis which has been propagated in the macroallocational realm of medicine will be much more difficult to implement at the casuistic level (18).

Not having come across any costs for the physician and being uncomfortable about the fact that patients carry the burden of risks and costs for medical services they receive without being able to envision or be accurately informed about benefits to be expected, it becomes clear that we have no valuative criteria to evaluate erogation, supererogation, self-interests, other-interests or any other parameter that might help us decide how to compare what is being given and what is being risked. At present, these insufficient parameters must be subjectively gauged and cannor serve to initiate any imperative language whatsoever Supererogation and altruism must remain the gracious virtues of physicians, to be celebrated but no? prescribed or demanded.

Requiring physicians to be altruistic is both dangerous and unfair. It is dangerous because it introduces an, albeit positive, separatist morality by demanding doctors to be better than other people, and better than they actually are. But if positive separatism is fostered, one will have to tolerate some negative consequences, for an equally separatist position might justify some forms of moral laxness, trying to place physicians in a position immune to the scrutiny of rational ethics. The unfair aspect of supererogation talk is that it requires something from physicians that goes beyond the actual demands placed on other members of the community, and that it also supersedes what physicians have contracted to do. By creating the obligation of altruism, one is shying away from increasing the stringency and expectations of medical rule-duties, at the same time going beyond recommendation or exhortation, in an effort to enforce certain acts by labelling them as obligations. Who, then, will be a good physician? The one exactingly carrying out his duties and benefiting patients by the mere adequacy of his action? Or the one who goes beyond this call and restricts self-interest in an openended escalation of supererogation? It is better to limit ethical demands on physicians to the feasible and controllable instead of unsettling professional conscience by demanding supererogatory standards that are hard to specify and therefore equally hard to fulfill. 
Michael $H$ Kottow $M D$, cand $M A$ (Sociology) is Associate Professor of Ophthalmology at the University of Chile, a member of a teaching hospital's ethics committee and author of a regular column on medical ethics.

\section{References}

(1) Thomson J J. A defense of abortion. In Cohen M, Nagel $\mathrm{T}$, Scanlon $\mathrm{T}$, eds. The rights and wrongs of abortion. Princeton: University Press, 1974: 3-22.

(2) Kleinig J. Good Samaritanism. Philosophy and public affairs 1976:382-407.

(3) Feinberg J. Supererogation and rules. In Thomson J J, Dworkin G, eds. Ethics. Cambridge: Massachusetts Institute of Technology, 1968: 391-411.

(4) Reeder Jr J P. Beneficence, supererogation, and role duties. In Shelp E E, ed. Beneficence and health care. Dordrecht: D Reidel Publishing Company, 1982: 83108.

(5) Nagel T. The possibility of altruism. Princeton: University Press, 1978:79.

(6) Rushton J P. Altruism and society: a social learning perspective. Ethics 1982; 92:425-446.

(7) Krebs D. Psychological approaches to altruism: an evaluation. Ethics 1982; 92:447-459.

(8) Sieghart P. Profession as the conscience of society. Fournal of medical ethics 1985; 11:117-122.

(9) Downie R S. Professional ethics. Fournal of medical ethics 1986; 12:64-65.

(10) Downie R S. Professional ethics - further comments. Journal of medical ethics 1986; 12:195-196.

(11) Gillon R. More on professional ethics. Fournal of medical ethics 1986; 12:59-60.

(12) Gillon R. Do doctors owe a special duty of beneficence to their patients? Fournal of medical ethics 1986; 12:171173.

(13) Freedman B. A meta-ethics for professional morality. Ethics 1978; 89:1-19.

(14) Freedman B. What really makes professional morality different: response to Martin. Ethics 1981;91:626-630.

(15) Martin $M$ W. Rights and the meta-ethics of professional morality. Ethics 1981; 91:619-625.

(16) Gewirth A. Professional ethics. The separatist thesis. Ethics 1986; 96:282-300.

(17) Lloyd G E R, ed. Hippocratic Writings. Harmondsworth: Penguin Books, 1978: 208.

(18) Agich G J. Economic cost and moral value. In: Agich G J, Begley C E eds. The price of health. Dordrecht: D Reidel Publishing Company, 1986: 23-42.

\section{News and notes}

\section{Two new Scope Notes}

Two new Scope Notes, Scope Note 2, Living Wills and Durable Powers of Attorney: Advance Directive Legislation and Issues, and Scope Note 13, The Aged and the Allocation of Health Care Resources, are available from the National Reference Center for Bioethics Literature.

The Scope Note series offers overviews of issues and viewpoints on current topics in biomedical ethics. Not comprehensive reviews, the papers are about 12 pages long and provide immediate reference to facts, opinions and relevant legal precedents for a wide audience that include scholars, journalists, medical and legal practitioners, students and interested laypersons.

Scope Note 2 about living wills and other advance directives contains up-to-date material on State statutes, sample generic living wills and durable powers of attorney for health care, along with annotated information about books and articles describing how interested persons can express choices about medical treatment if they become unable to make decisions due to poor health.

Scope Note 13 provides information about health care rationing and presents different suggestions from the literature offered to achieve a fair or just allocation of available resources.

The Scope Notes are available for $\$ 3$ each, prepaid, from the National Reference Center for Bioethics Literature, Kennedy Institute of Ethics, Georgetown University, Washington, DC 20057, or telephone 202-687-6738. 